\title{
"Roid-Rage" at the Cellular Level: Abolition of Endogenous Cardioprotection by Anabolic Steroids Reveals New Links Between the RAAS and Cardiac $K_{\mathrm{ATP}}$ Channels
}

\author{
Editorial to: " $\mathrm{AT}$ 1 and Aldosterone Receptors Blockade Prevents the Chronic Effect \\ of Nandrolone on the Exercise-Induced Cardioprotection in Perfused Rat Heart Subjected \\ to Ischemia and Reperfusion" by S.R. Marques-Neto et al.
}

\author{
Adam J. Chicco • David A. Brown
}

Published online: 28 February 2014

(C) Springer Science+Business Media New York 2014

Substantial evidence suggests that androgenic anabolic steroids (AAS) have deleterious effects on many body tissues, but their influence on endogenous mechanisms of cardioprotection is poorly understood. In the current issue of CDT, Marques-Neto et al. present a study examining the mechanisms by which AAS attenuate the protective effects of exercise training on myocardial ischemia/ reperfusion injury [1]. They chose to focus on the roles of angiotensin II and aldosterone, given the wellestablished stimulatory effect of AAS on the renin angiotensin-aldosterone system (RAAS) and the role of this system in the pathogenesis of myocardial injury. Exercise-trained rats were co-administered nandralone (AAS) along with losartan or spironolactone to block $\mathrm{AT}_{1}$ or aldosterone receptors, followed by evaluation of post-ischemic function and infarct size in isolated perfused hearts. Their results show that nandralone abolishes the benefits of exercise training on post-ischemic function and infarct size reduction, and that both RAAS blockers restore these benefits, confirming the hypothesized role of the RAAS in the AAS-induced suppression of exercise-induced cardioprotection.

\footnotetext{
A. J. Chicco $(\square)$

Departments of Health and Exercise Science and Biomedical Sciences, Colorado State University, Fort Collins, CO, USA e-mail: adam.chicco@colostate.edu

D. A. Brown

Department of Physiology, Brody School of Medicine and the East Carolina Diabetes and Obesity Institute, East Carolina University, Greenville, NC, USA

e-mail: brownda@ecu.edu
}

In this study, Marques-Neto et al. link the preservation of cardioprotection to maintenance of myocardial sarcolemmal ATP-sensitive potassium ( sarcK $_{\mathrm{ATP}}$ ) channel expression. sarcK $_{\text {ATP }}$ channels are highly expressed in the cardiac sarcolemma, and open in response to local changes in nucleotide content (reviewed in [2-4]). A growing body of literature supports a positive correlation between sarcK $_{\mathrm{ATP}}$ expression and cardioprotection [5, 6]. Preconditioning conferred by exercise is associated with enhanced sarcK $_{\text {ATP }}$ channel subunits [7], and genetic loss of sarcK $\mathrm{K}_{\mathrm{ATP}}$ channels confers exercise intolerance and poor adaptation of the heart to stress [8].

sarcK $\mathrm{K}_{\mathrm{ATP}}$ channel expression is also believed to mediate sex-dependent protection against cardiac injury. While women are known to exhibit reduced risk of cardiovascular events and associated mortality compared to males, the molecular mechanisms of this sex-dimorphism remains incompletely understood [9-11]. Animal studies have demonstrated an intrinsic resistance of the female heart to ischemia/ reperfusion injury, which has been linked to a higher expression of sarcK $\mathrm{ATP}_{\mathrm{AT}}$ channel subunits in the female versus male heart [6, 12-14]. Estrogen upregulates sarcK $\mathrm{ATP}_{\mathrm{AT}}$ channel subunit expression in cardiomyocytes [15], suggesting a potential mechanism for its protective effects in the heart. Clinical studies indicate that pharmacological interventions that block

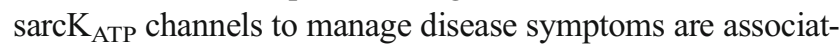
ed with increased cardiovascular mortality [16, 17], further suggesting an important protective role of these channels on cardiovascular health.

Despite the relationship between cardiac tissue health and sarcK $\mathrm{ATP}_{\mathrm{AT}}$ expression, the cellular mechanisms responsible for altering the expression of these channels are not clear. The study by Marques-Neto et al. implicates the RAAS in androgenic suppression of $\operatorname{sarcK}_{\mathrm{ATP}}$ and exercise-induced 
cardioprotection. This adds to an ever-growing list of pathogenic effects mediated by hyperactivity of this system, including maladaptive cardiac remodeling, kidney failure, vascular endothelial dysfunction, and hypertension. Estrogen has been shown to attenuate the pathogenic effects of RAAS on these pathologies [18], implicating their interaction in the cardioprotected female phenotype. Interestingly, sarcK $\mathrm{K}_{\text {АTP }}$ channel activation attenuates the effects of RAAS activation on maladaptive cardiac remodeling and endothelial dysfunction $[5,19]$, processes known to exhibit sex-dimorphic risk profiles [11, 20, 21].

It is intriguing to speculate that sarcK $\mathrm{K}_{\mathrm{ATP}}$ channel activity is required for other protective effects of estrogen and female sex on the cardiovascular system. This hypothesis merits further investigation, as such studies may reveal new therapeutic applications for sarcK $\mathrm{KTTP}_{\mathrm{AP}}$ channel openers and shed light on the molecular underpinnings of cardiovascular sexdimorphisms. Another exciting area for future study is to determine the involvement of other intracellular receptors that respond to RAAS signaling. For example, recent work identified a mitochondrial angiotensin receptor [22], which may be centrally involved in several paradigms of cardioprotection by influencing nitric oxide-dependent signaling. Finally, studies aimed at elucidating the interaction of estrogens, androgens and RAAS signaling on sarcK $_{\text {ATP }}$ channel expression may help to unravel the complex biological effects of these systems that could simplify future thinking and improve therapeutic approaches to cardiovascular disease.

\section{References}

1. Marques-Neto SR, Ferraz EB, Rodrigues DC, et al. $\mathrm{AT}_{1}$ and aldosterone receptors blockade prevents the chronic effect of nandrolone on the exercise-induced cardioprotection in perfused rat heart subjected to ischemia and reperfusion. Cardiovasc Drugs Ther 2014;28: this issue.

2. O'Rourke B. Myocardial K(ATP) channels in preconditioning. Circ Res. 2000;87(10):845-55.

3. Brown DA, Moore RL. Perspectives in innate and acquired cardioprotection: cardioprotection acquired through exercise. J Appl Physiol. 2007;103:1894-9.

4. Alekseev AE, Hodgson DM, Karger AB, Park S, Zingman LV, Terzic A. ATP-sensitive $\mathrm{K}+$ channel channel/enzyme multimer: metabolic gating in the heart. J Mol Cell Cardiol. 2005;38:895-905.
5. Kane GC, Liu XK, Yamada S, Olson TM, Terzic A. Cardiac KATP channels in health and disease. J Mol Cell Cardiol. 2005;38:937-43.

6. Jovanovic A. Ageing, gender and cardiac sarcolemmal K(ATP) channels. J Pharm Pharmacol. 2006;58:1585-9.

7. Brown DA, Chicco AJ, Jew KN, et al. Cardioprotection afforded by chronic exercise is mediated by the sarcolemmal, and not the mitochondrial, isoform of the KATP channel in the rat. J Physiol. 2005;569(Pt 3):913-24.

8. Zingman LV, Hodgson DM, Bast PH, et al. Kir6.2 is required for adaptation to stress. PNAS. 2002;99:13278-83.

9. Mahmoodzadeh S, Fliegner D, Dworatzek E. Sex differences in animal models for cardiovascular diseases and the role of estrogen. Handb Exp Pharmacol. 2012;214:23-48.

10. Ng MK. New perspectives on Mars and Venus: unravelling the role of androgens in gender differences in cardiovascular biology and disease. Heart Lung Circ. 2007;16:185-92.

11. Pilote L, Dasgupta K, Guru V, et al. A comprehensive view of sexspecific issues related to cardiovascular disease. Can Med Assoc J. 2007;176:S1-S44.

12. Chicco AJ, Johnson MS, Armstrong CJ, et al. Sex-specific and exercise-acquired cardioprotection is abolished by sarcolemmal KATP channel blockade in the rat heart. Am J Physiol. 2007;292: H2432-7.

13. Johnson MS, Moore RL, Brown DA. Sex differences in myocardial infarct size are abolished by sarcolemmal KATP channel blockade in rat. Am J Physiol. 2006;290:H2644-7.

14. Brown DA, Lynch JM, Armstrong CJ, et al. Susceptibility of the heart to ischaemia-reperfusion injury and exercise-induced cardioprotection are sex-dependent in the rat. J Physiol. 2005;564(Pt 2):619-30.

15. Ranki HJ, Budas GR, Crawford RM, Davies AM, Jovanovic A. 17Betaestradiol regulates expression of K(ATP) channels in heart-derived $\mathrm{H} 9 \mathrm{c} 2$ cells. J Am Coll Cardiol. 2002;40:367-74.

16. Brady PA, Jovanovic A. The sulfonylurea controversy: much ado about nothing or cause for concern? J Am Coll Cardiol. 2003;42: $1022-5$.

17. Brady PA, Terzic A. The sulfonylurea controversy: more questions from the heart. J Am Coll Cardiol. 1998;31:950-6.

18. Xue B, Johnson AK, Hay M. Sex differences in angiotensin II- and aldosterone-induced hypertension: the central protective effects of estrogen. Am J Physiol Regul Integr Comp Physiol. 2013;305: R459-63.

19. Gao S, Long CL, Wang RH, Wang H. K(ATP) activation prevents progression of cardiac hypertrophy to failure induced by pressure overload via protecting endothelial function. Cardiovasc Res. 2009;83:444-56.

20. Novella S, Dantas AP, Segarra G, Medina P, Hermenegildo C. Vascular aging in women: is estrogen the fountain of youth? Front Physiol. 2012;3:165.

21. Thireau J, Aimond F, Poisson D, et al. New insights into sexual dimorphism during progression of heart failure and rhythm disorders. Endocrinology. 2010;151:1837-45.

22. Abadir PM, Foster DB, Crow M, et al. Identification and characterization of a functional mitochondrial angiotensin system. PNAS. 2011;108:14849-54. 